\title{
DOCUMENTOS
}

\section{La Relación de un Ciego, Pieza Dramática de la Epoca Colonial}

Aunque las letras hispanoamericanas cuentan con valiosas aportaciones bibliográficas e importantes estudios dedicados a escritores $\mathfrak{u}$ obras individuales, los estudios y la bibliografía del teatro durante la época colonial quedan incompletos. ${ }^{1}$ José J. Arrom, experto en el teatro virreinal, ha comentado sobre la parvedad de obras teatrales de comienzos del siglo XVII: "era tal la abundancia de las piezas que continuamente llegaban de España, que resultaba vano esfuerzo todo intento de competencia de parte de los escritores locales."2 $\mathrm{Si}$ las bibliotecas y archivos públicos y privados fueran puestos a disposición del investigador de manera sistemática, se podrỉa conocer mejor la historia teatral de los tres siglos de la dominación española en América.

En un volumen misceláneo de manuscritos que se conserva en la Biblioteca Nacional de México, 3 figura una curiosa obrita titulada Relación de un ciego, que no es, como se pensará considerando el título, una de las muchas relaciones de sucesos históricos hechas por los cantores ciegos, ${ }^{4}$ sino una deleitosa obra de teatro. No creemos que hasta la fecha nadie haya fijado su atención en este opúsculo e igualmente ignoramos si se ha redactado una descripción bibliográfica del contenido del volumen, aunque varios eruditos mexicanos se han ocupado de una composición de Luis de Sandoval Zapata. ${ }^{5}$ Se trata de un volumen facticio reunido en el siglo XIX, pero algunos textos incluidos se basan en originales del siglo XVII. La caligrafía de los cartapacios revela que los amanuenses fueron varios, algunos tal vez de mediados del siglo XVIII. Todo el códice merece un detenido estudio; hoy sólo nos limitamos a editar la Relación.

La Relación de un ciego, escrita para las celebraciones navideñas en un jovenado de monjas, no carece de atractivo. Se destaca la 
sencillez de la obra en los dos personajes, en el metro octosilábico con asonancia en los versos pares y por el uso de voces mexicanas. Se perciben, si no huellas, reminiscencias de los autos de Navidad, tan famosos en la metrópoli desde el siglo XV, y también de las populares pastorelas y posadas de la Nueva España, 6 testimonio de la continuación en el Virreinato de una tradición bien arraigada en España.

Al copiar la Relación hemos conservado la ortografía del original con las salvedades siguientes: se regularizan el uso de mayúsculas, los acentos y la puntuación; se imprimen en cursiva las letras añadidas, resolviendo asĩ las abreviaturas. Para facilitar la lectura incluimos al final del tex to breves comentarios sobre algún vocablo. ${ }^{7}$ Se publica la Relación con la debida autorización del Licenciado Ernesto de la Torre Villar, Director de la Biblioteca Nacional, para quien dejamos pública constancia de nuesto agradecimiento.

\section{Oakland University}

WILLIAM C. BRYANT

f $1^{\mathbf{r}}$ ] Relación de un ciego que se usó en el juvenado / la noche de su biaje. Hablan en ella el ciego y / su lazarillo, el que lo saca como agarrado de la mano.

Lazarillo: Con lisencia, madrecitas, que mi tata ba ha salir ha echar una relación que las ha de convertir. Bamos, tata, enpieza ya ha mover los corazones para que nos den siquiera una grueza de azitrones. Siego: $\quad$ El sol disen que ha salido. ¡Hay! ¿De qué color será?

¿Si será color de viernes ho color de Navidad? Las monjas de este convento disen que parditas son. Según me lo han esplicado serán como un chorizón. Tanbién me han dicho que ayunan. ¡Hay! ¿Qué grande voverǐa tener como camaleones sus barrigas todo el día!

Tanbién disen que se azotan. 
Esto ¿a quién le ha de quadrar?

Pues esta rezeta biene mui mal ha mi paladar. Aquí barren, aquí lavan y en mucha vigilia están por lo que creo ciertamente que son de tapinserán. Si yo no me hallara ciego, capuchinito sería, pero con la condición de comer todito el día. Tanpoco me he de azotar. Si quieren que yo esté aquí, en lugar de diciplina doble ración para mí. De almuerzo no más me dan dos libras de chocolate, diez $u$ onse tortas de pan $y$ un moyete de remate. Para comer me darán un bagrecito chiquito que tenga desde el vigote dos baras y un pedacito, vn clascalito de huevos, parte de ellos estrellados, otros pasados por agua y los demás regañados. Pero, ¿porqué tan poquito he de comer, si me alcanza la apetencia para que entre lo que llaman la pitanza? De este plato me darán diesiocho ho beynte bolitas de papas porque las hasen demaciado chiquitas. Para guardar esta regla y no acavarme en un día, me yré ha beber el café que hasen en la enfermeria. Vna cosa mui medida será para colación 
que se encierra en treinta huevos y dos tortas de mamón. Madres, seguid estas reglas que este pobre ciego os da y así estaréis muchos años siguiendo comunidad.

Pero dejando de cuentos y de ensartar desatinos, llébame, hijo, a que adoremos a los santos peregrinos.

Lo lleva el Lazarillo donde está el Viaje.

Siego: ¿Qué dises, hijo? ¿Ya estoi en un buen lugar parado para adorar en el bientre de María al vervo humanado?

Lazarillo: Ya estás mui bien aquí, tata.

Diles tu razonamiento $y$ no te quieras trepar hasta sobre el Nacimiento.

Siego: Yo te adoro, Jesús Niño, en ese cristal sagrado de donde habéys de salir al mundo ha ser despreciado. A este niño sì conosco aunque siego. Y sé quién es, pues soi christiano al derecho y tanbién por el rebez. $\mathrm{Y}$ ha ti, divina María, te suplico, gran Señora, nos anpares en la bida y también en la última hora. $\mathrm{Y}$ a Ti, Padre Putativo del Dios honbre anondado, te pido que en la agonía no os quitéis de nuestro lado.

Por último pediremos con la mayor humildad ha estos güéspedes sagrados por nuestra comunidad. Los pido por nuestros padres, capellán y peregrino, 
ynflámenlos más y más en fuego de amor divino. A nuestra Madre conceda mucha gracia y fortaleza para que llebe su cruz, que Vos sabés quánto pesa. A nuestra Madre Vicaria manténganla alentadita para que pueda ayudarle en todo a la pobrecita. Para las enfermas pido una gran conformidad para que lleve cada una con gusto su enfermedad.

Se vuelve a las religiosas y dise:

No he pedido por las sanas porque enfermas todas son, pues ya este nuestro convento es de la Vicitación.

Aquí quería yo acabar, pero ¡hai por hair un tintín de que no hecho petición por el padre don Fermín! ya en el corazón me da que ha sido su yntersesora la Madre Sor Trinidad. Haced a este santo padre más santito de lo que es, mas que se acueste tenprano y diga misa a las dies. Perdonen, madres, las faltas que han tenido en la ocasión el ciego y su lazarillo en tan sagrada mición. Por fruto, señoras, pido de limosna un gran turrón con su plátano pasado y demás de colación.

Lazarillo: Bámonos, tata, corriendo que bienen mis hermanitas 


\author{
ha ofrecerle al Niño Dios \\ unas cosas mui bonitas.
}

Fin.

v. 4, convertir: divertir.

v. 8 gruesa: "En Tabasco y regiones limitrofes de Chiapas y Campeche, gorda; tortilla grande y de mucho espesor, de uso común en la alimentación campesina."

v. 8, azitrones: "biznaga confitada."

v. 28, tapinserán: variante de tapicerán, "nombre vulgar de una planta julianácea."

v. 40, moyete: "Nombre genérico que se da a los escarabajos voladores, vulgarmente."

v. 45, clascalito: "Del azt. tlaxcal, tortilla."

v. 52, pitanza: "acción y efecto de pitar o fumar."

v. 64, mamón: "Biscocho blando de harina y huevo; especie de marquesote o panqué."

\title{
NOTAS
}

1. Modelo de lo que hay que hacer con la obra de otros escritores coloniales es Irving A. Leonard, Pedro de Peralta Barnuevo. Obras dramáticas, con un apéndice de poemas inéditos, Santiago de Chile, 1937. Para las importantes contribuciones a la bibliografía del teatro virreinal, véanse los repertorios teatrales en México y Lima citados en la bibliografía en Homage to Irving $A$. Leonard. Essays on Hispanic Art, History and Literature, editado por Raquel Chang-Rodrïguez y Donald A. Yates, Staten Island, 1977, pp. 11-18.

2. Historia del teatro hispanoamericano (época colonial), México, 1967, p. 50. Cfr. Enrique Anderson Imbert, Historia de la literatura hispanoamericana, I, $3^{a}$ ed., México, 1961, pp. 87-8 y Anthony M. Pasquariello, Homage to Irving $A$. Leonard, pp. 105-6.

3. Actualmente lleva la signatura 1608 (antes 86-[082.2]).

4. V. Antonio Rodriguez-Moñino, "Cristobal Bravo, ruiseñor popular del siglo XVI. Intento bibliográfico (1572-1963)," Homenaje al Profesor Alarcos, Valladolid, 1966, pp. 411-33 y nuestro "Sor Juana Inés de la Cruz y la literatura de cordel del siglo XVIII. Noticias bibliográficas," Anuario de Letras, XII (1975), 273-6.

5. Inclúyese en el volumen la "Relación fúnebre a la infeliz, trágica muerte de... Alonso de Avila y Alvaro Gil González" de Luis de Sandoval Zapata. Sobre este romance v. José Pascual Buxó, Muerte y desengaño en la poesía novohispana (siglos XVI y XVII), México, 1975, pp. 6, 117-28 y del mismo autor "Sobre la Relación fúnebre..." Anuario de Letras, IV (1964), 273-54. 
6. Sobre las pastorelas y posadas cfr. L. H. Quackenbush, "The Other pastorelas of Spanish American Drama," Latin American Theatre Review, 6/2 (1973), 55-63 y Willis Knapp Jones, Behind Spanish American Footlights, Austin, 1966, pp. 460-62.

7. En las notas citamos el trabajo de Francisco J. Santamarĭa, Diccionario de mejicanismos, $2^{\mathrm{a}}$ ed., México, 1974.

W.C.B. 
